\title{
Cultivating nurses' potential to incorporate assessment and minimisation of the consequences of the effects of illness into presence
}

\author{
Christine Joy Mercer \\ School of Nursing and Health Studies, Waiariki Institute of Technology, Rotorua, New Zealand
}

Correspondence: Christine J oy Mercer. Address: School of Nursing and Health Studies, Waiariki Institute of Technology, Private Bag 3028, Rotorua, New Zealand. Email: Christine.Mercer@waiariki.ac.nz.

Received: J une 28,2012

DOI : $10.5430 /$ jnep.v3n6p134
Accepted: October 25, $2012 \quad$ Online Published: January 8, 2013

URL: http://dx.doi.org/10.5430/jnep.v3n6p134

\section{Abstract}

Background: In 2006 a phenomenological study was completed which explored the experiences of 14 participants (supportive spouses) each of whom had a partner who was hospitalised in a non-local tertiary centre.

Methods: Data were gathered through unstructured interviews with the supportive spouse. Individual stories were analysed, underpinned by Heideggerian philosophy of understanding, and interviews with new participants continued until patterns of the experiences emerged. Three overall themes emerged from the research, 'being in suspense', 'living day by day amid the unknown', and juggling the unknown when the couples were separated emotionally from those who surrounded them; mainly because it was the everyday for hospital personnel, but unknown for the couples. Although they did not clearly articulate this, the catalyst for managing their non-local hospital experiences was bound in the readiness, or lack of readiness of nurses to engage in therapeutic interactions. This paper is focussing on the third of the overall research findings; that is of the importance of a therapeutic relationship.

Results: A catalyst for managing hospitalisation is bound in the readiness of nurses to engage in therapeutic interactions (presence). Patient groups recognise this phenomenon when they perceive the nurse can appreciate the patient's world view. Despite theorists clearly identifying caring (and therefore presence) as the key concept of nursing practice, the concept of presence is no longer reflected in the everyday world of nursing. Increased technological demands on nurses have resulted in nursing losing sight of its unique characteristics. Nursing needs to move beyond being measured in terms of technical competency, and should ensure instead that nurses develop confidence in articulating what constitutes the holistic characteristics of care. On emphasising the need for greater emphasis of presence to practice, nurses need to be mindful of the value placed on care; a re-emphasis of presence in nursing education programmes; and, modelling of care in practice.

Conclusions: Academic and clinical nurses need to argue that presence is the defining principle of nursing care, and, therefore, must be included in assessments. The inclusion of presence as a competency will substantiate the argument that nursing is more than the technical-based frameworks and will underscore that presence is the key underpinning principle of optimal care.

\section{Key words}

Nursing care, Nursing assessment, Presence, Modelling care 


\section{I ntroduction}

In 2006 a phenomenological study was completed which explored the experiences of 14 participants (supporting spouses) each of whom had a partner who was hospitalised in a non-local tertiary centre. Paul, (pseudonym) found juggling his business and home life, including looking after two young children, a challenge during the time that Glenys was hospitalised a 3 hour drive away from home. Paul and Glenys decided that he would not accompany her, as they wanted to create as much normality for the children as possible. Edward and Trudie also tried to determine the best options for the entire family when Trudie required out-of-town hospitalisation. In addition, Edward, was reluctant to jeopardise his work, and struggled to balance his commitments to Trudie, and his work. Victoria had to make alternative arrangements for her business when Don was suddenly admitted to the distant tertiary setting. Zoë, who was $600 \mathrm{~km}$ from home, found accommodation in the nurses' home which had been converted to accommodate relatives. Although adequate, the single beds in single rooms added to Zoë's sense of loneliness as she lay awake at night listening to the rescue helicopters retrieving critically ill patients, wondering if her husband would survive the emergency surgery.

\section{Study and findings}

The study was underpinned by Heideggerian philosophy of understanding that occurs when individuals can make sense of their experiences in the context of life-worlds ${ }^{[1]}$. Following approval from regional ethics committees, data were gathered using unstructured interviews with the supportive spouse. On the occasions that the partner who was ill also attended the interview, additional rich stories were gathered. The individual stories were analysed, and interviews with new participants continued until patterns of the experiences emerged. Three overall themes emerged from the research, 'being in suspense', as the families anticipated the treatment, or for the outcome of the treatment itself (including an intense fear that the partner would die); 'living day by day amid the unknown', which included times when the supporting spouse struggled to juggle home and the sick partner, separated by geographical distances, and the final theme related to juggling the unknown when the couples were separated emotionally from those who surrounded them; mainly because it was the everyday for hospital personnel, but unknown for the couples. Although they did not clearly articulate this, the catalyst for managing their non-local hospital experiences was bound in the readiness, or lack of readiness of nurses to engage in therapeutic interactions. This paper is focussing on the third of the overall research findings; that is of the importance of a therapeutic relationship.

The manner in which health professionals engage in therapeutic interactions influence the ability of families to cope during critical incidents ${ }^{[2]}$, a bearing described as presence ${ }^{[3]}$. However, the components that constitute therapeutic relationships and, therefore, presence, are often so subtle that at best, the uninformed fail to see them, or at worst they are viewed as coming from the heart with no scientific knowledge basis ${ }^{[4]}$. Like beauty, and like quality, the concept of presence is elusive but it can be recognised when it is experienced in the therapeutic relationship. Furthermore, it is more than 30 years since the notion of presence was first postulated, so the definition may need to be modified to both incorporate, but challenge the changing face of contemporary nursing. The purpose of this paper is to not only explore the concepts of presence, it is also to explore the strategies needed to explicate presence as a key underpinning principle of nursing care.

\section{I ntroduction to presence}

The paper begins with a critical examination of the definitions of presence and underpinning theoretical works which explain the relationship between presence and care. While theories developed by Watson and Swanson describe nursing presence, the language currently used to describe nursing does not include the concept of presence. The concept appears to have been swept aside with the increase of technology; yet it is proposed that without presence nurses will become mere technicians, and not acknowledge their role in assessment to anticipate care. With the 2006 research that examined the experiences of non-local hospitalisation in mind, there is a need to revisit the essential elements of presence to not only acknowledge the role of impact that presence has in restoring health ${ }^{[5]}$, especially in the provision of secondary care, but 
also to ensure that nurses are encouraged to articulate their unique role in the provision of health care. The intent of this paper is to capture the essence of assessment that underpins presence in nursing, and describe the way nurses can use presence in a positive and curative way that is unique to the domain of nursing. It is reasoned, therefore, that presence is to nursing as nursing is to healing relationships.

In presenting an argument to place a greater emphasis of presence in nursing practice, three aspects of applying presence need to be considered. These are the value placed on care; a re-emphasis of presence in nursing education programmes; and modelling of care in practice. In modelling this care in practice, the notion of "assessment for the potential or nursing care to minimise the effect of effects of illness" needs to be incorporated into the concept of presence.

\subsection{Defining presence in contemporary models of care}

Presence has been described as "being with or being there...[entering] into the world of the other, to see that world from the other's perspective" ${ }^{[5]}$. Presence has also been detailed as specific caring behaviours related to the expectation that nurses will communicate, respect, inform, aid, comfort, empathise and be seen ${ }^{[6]}$. When health professionals give a little of self, and connect with the patient's experiences, they manifest presence, thereby enhancing the patient-practitioner relationship ${ }^{[6]}$. Nurses can also demonstrate presence by providing holistic care for the patient group rather than focussing only on the sick individual ${ }^{[3]}$. While viewing the health/interactions through the eyes of others in a key element of presence, the concept also requires nurses to assess to determine the potential of an illness/ or event, and plan their care to minimise the effect of the illness or event.

Articulation of the characteristics of presence makes sense as this enables nurses to recognise these characteristics as foundations for competency to practice ${ }^{[6]}$. However, current funding models for secondary care are based on technology and medical sciences, not human sciences that consider times of patient's vulnerability or the need for healing relationships ${ }^{[8]}$. Unless nurses acknowledge their role in presence, and the characteristics of critical thinking during assessment as a core component of presence, the core of nursing itself will disappear, and not become apparent until it is missing ${ }^{[1]}$. Ward-based nurses are the only health professionals who stay in the department for their entire working day, with every other health professional adopting a consultancy role who attends to the patient for a brief period of time. Therefore the physical presence can result in assessment of clients' needs becoming an invisible component of nursing. When one nurse consultant spent some time with the patient, she was not recognised as a nurse with Carol saying "...the lady came and taught me what to do" ${ }^{11}$. The challenge remains, therefore, for those who fund clinical practice and those who provide clinical care to find congruent meanings of the characteristics of presence.

Those who fund care base their funding on a predetermined length of time spent with the patient. Models of management that are driven by costs and economic gains, on-going tensions between philosophical approached to care and unsustainable nurse-patient ratios have not only dispirited nurses' ability to care, but have also detoured nurses away from caring ${ }^{[8]}$. In contrast, nurses know that the length of time to 'be present' with the patient cannot be predetermined. In contrast, effective communication can not be measured in time-frames when the nurse is assessing a patient with a newly diagnosed cancer, as exemplified in the following extract. There were a few times when you were not sure what the heck was going on. It was overwhelming. [The specialist] was talking all this jargon, and I was thinking "oh God" [1, p 170]. Effective communication requires listening in a manner that generates genuine concern to understand patient's concerns ${ }^{[10]}$. In contrast, as illustrated in the following quote, care is more often appraised by patients in terms of the length of the physical presence of nurses. They never, they hardly ever spoke to me...A lot of the time we were left alone ${ }^{[1]}$. Furthermore, when patients view the nurses busy caring for other patients, 'busy-ness' is measured by the occurrence of activities, by nurses physically doing things to or for patients; it is not calibrated in activities away from the bedside such as the review of patient notes or cases ${ }^{[10]}$, as evidenced in the following excerpt...[The nurse said] 'we are very busy'. My son said 'you look very busy all sitting around there having a chat' ${ }^{11]}$. Because nurses are always on the ward, the role that nurses have in conducting their assessments, and in case review to plan care is not apparent.

Although those who finance health professionals continue to question whether humanity makes a difference to patient care $^{[5,11]}$, unless the caring-healing processes are returned to nursing, and presence is included in definitions of quality 
care, money will continue to be wasted ${ }^{[8]}$. This is particularly relevant if anticipatory patient care is overlooked, and the patients' needs are determined without reference to the client's reality ${ }^{[11]}$, or based on caring science ${ }^{[12]}$. Organisations cannot afford to exclude humanity from patient care.

\subsection{Models of presence in caring}

It is argued that the key components of care are nurturing to facilitate health ${ }^{[4]}$; connecting with the other person; and, in developing the nurse patient relationship, endorsing the other person's sense of value, and the nurse's personal commitment and responsibility to care. In nurturing the relationship, the nurse can convey to patients that they and their experiences matter ${ }^{[4]}$; they can transmit that the nurse can appreciate the patient's world view. In contrast, the following excerpt demonstrates how nurses do not always engage in caring for the client group. Well it was a stress and strain on the rest of the family when he was in and out of hospital as often as he was...At that time I was a bit resentful because it seemed to me that he was being looked after, but nobody was looking after me...It is not only the patient who needs looking after (Winifred cited in 1 p.133). Presence, therefore, means to give time, listen attentively and be responsive to the patients' needs ${ }^{[3,10]}$. Central to being responsive to clients' needs is the assessment to identify potential problems linked to the disease trajectory ${ }^{[13,14]}$. Thus nursing presence and caring not only involves the humanity of the nurse, it also potentiates healing ${ }^{[15]}$.

Although the concepts of caring are taught in the classroom ${ }^{[16,17]}$, nurses are torn between applying the nursing frameworks that they have been taught (and to which they strive to cling) whilst struggling to survive in a professional world dominated by bio-medical models ${ }^{[8,18,19]}$. Nurses are seemingly increasingly reluctant to work in hospital settings because they are unable to practice their own profession in an environment that is dominated by "medical-economictechnologicalinstitutional foci" over person-centred care that fosters "human-to-human relationships and caring-healing processes and practices” ${ }^{[19]}$. They are struggling not to become overwhelmed with cure-centric approaches to care which stifle discussion about what constitutes nursing, and what nurses $\mathrm{do}^{[7]}$. When descriptions of nursing focus on the physical components of care ${ }^{[19]}$, they become seen as accurately depicting nursing. But while such descriptions may shed light on the functional roles of nurses, the language used does not capture the presence of nursing ${ }^{[4]}$. The consequence is that nurses are no longer able to readily describe what they are doing in terms of presence and instead have recourse to technological accounts of task specifics, therefore less able to disentangle nursing care from services provided by medical personnel, social workers, or health care assistants.

\subsection{Value placed on presence}

In the current climate of care, greater emphasis is placed on the development of technical competency than on the recognition of presence ${ }^{[20]}$. For example, nurses are under increasing pressure to cannulate, undertake phlebotomy, and record ECGs. The focus on the acquisition of technical skills has forced nurses to define nursing in terms of tasks, and overlook the invisible components of assessment underpinned by attending to, and being with their patient groups. In addition, many students are enculturated to believe that technical skill acquisition is critical to being a 'real' nurse ${ }^{\text {[21] }}$. Nursing needs to move beyond being mainly measured in terms of technical competency; the role of assessment in minimising the potential of the effects of illness nursing must be brought to the fore. Unless nurses differentiate between these tasks and assessments they undertake associated with the provision of nursing care, they are only completing delegated medical tasks; becoming automatons, not engaging in presence-orientated nursing. For example ... They only do their job...sometimes Gerry didn't even have his stockings on, and I had to put those on him. I said, "You should have asked the nurse". It's that, just little things I think that, you know... I mean I know it's still medical treatment that he had to wear those stockings. They needed to be there, and they should have seen that they were there; that they were on him. But it wasn't there. And he said, “I can't get them on” and I said, “ask the nurses. That's what they're there for”. But that's what they should have been doing in the first place...I don't feel that they [anticipate] (Queenie cited in 1 p.168).

While patients expect nurses to be technically competent, and to perform nursing tasks in a prompt, skilled manner, they also expect them to remain vigilant and to refer when appropriate ${ }^{[14,21]}$; they need to know what works and when to act which constitutes another dimension of presence ${ }^{[6]}$. Carol's story exemplifies a lack of appropriate actions by a nurse, 
reporting [..he had his operation on a Monday]. By Wednesday... his temperature is up; something is happening here. So I said to the nurse, "something is happening, his temperature is going up". "Oh it’s not going up" [in response]. Anyway she didn't do much about it. Carol later discussed this with the doctor who acknowledged the pyrexia. While caring without a scientific nursing knowledge base is perilous to nursing ${ }^{[12]}$, it is equally perilous to nursing if the profession becomes authenticated through the acquisition of technical skills alone ${ }^{[18]}$. The lack of acknowledgment from the nurse resulted in the relatives perceiving that the nurse was occupied in perfunctory routine practice, and not assessing for the potential of the at risk phenomena.

Presence, including the characteristic of communicating in an attentive way ${ }^{[10,16]}$ certainly cannot be valued if it is not recognised. The lack of attentive communication added to the despair expressed by the participants in the current study...I found that the nurses were a bit arrogant. Because they think that they know the best. They just think it is alright (Queenie, cited in 1 p.4). While many tools for measuring workforce requirements attempt to quantify nursing activities ${ }^{[9]}$, nurses' responses or commitment to care has been described as the healing power of compassion that alleviates suffering by commitment and good will, and respect for 'small' things ${ }^{[22]}$. However, it is contended in this paper that the small things are not an optional extra; they are core components of nursing. A consciousness of the concept of presence must be raised in nursing programmes so that student nurses become aware of the concepts and subsequently supported by hospital nurses so that both groups appreciate how a failure to be there and be present when nursing their patients impacts on patients' perceptions of quality care.

\section{Returning care to clinical education}

Benner's ${ }^{[23]}$ classic work on the progressive nature of the development of clinical wisdom underpins the challenge of role modelling presence in practice. As Benner explained, the acquisition of skills progresses through five stages of competency from Novice (student nurse), Beginner Practitioner (New Graduate), Competent, Proficient and finally Expert Nurse. The catalyst for successful progression through the novice to expert competencies is founded in education and honed by time ${ }^{[24]}$. Meanwhile, patients measure caring not only by identified technical ability, but also by the ability of nurses to act confidently ${ }^{[24]}$. In other words, if the patients measure presence through the nurses' confident demeanour while conducting requisite technical skills, which can only be achieved over time. In recognition of the novice to expert continuum $^{[23]}$, as nurses mature in their clinical competency, they can develop confidence to be with their patients, as well as be technically competent. Hospital nurses who manifest presence not only hear the patient's concerns, but also know when to sit silently with the patient ${ }^{[10,14]}$. Findings from a Scandanavian study ${ }^{[25]}$ concluded that components of being a good nurse not only include being skilled and competent, but also included the capacity to care for others in an empathetic humanistic manner. These findings are supported in the current research as explained...From my point of view, whenever we saw the nurses, they always included me...talked to me as well as Glenys. I always felt I wasn't there, surplus to requirements [Paul, cited in 1, p.185].

However, over time nurses forget that the patient may be experiencing the illness episode for the first time; for the nurse this has become everyday and therefore normal. Presence requires the nurse to see things through their patients' eyes. For example Victoria was upset that her husband had been sent unattended to the shower on the second day with a throw away comment of “Oh I'm sure he will be alright” [Victoria cited in1, p.177] Victoria felt compelled, but resented, to come in on a daily basis to shower her husband herself.

Coupled with the reality that working with sick people has become normal for nurses, the increased casualisation of the workforce, and subsequently increasing workloads ${ }^{[26]}$, leave the hospital nurses exhausted. This means that as exhausted nurses struggle to complete the allocated technical tasks, little time remains for engaging in the interpersonal skills required for demonstrating presence. While nurses may touch their patients to perform nursing procedures, nurses who are exhausted may not have the emotional energy to touch in a caring way ${ }^{[24]}$. There is incongruence between the reasons they went nursing, and the reality of providing care in hospital settings. If exhaustion is either perceived or felt among the clinical nurses, their ability to be present becomes blunted. For example, when a patient had a cardiac arrest, one research 
participant in the current study recalled being horrified that a nurse stated, “Oh I don't have to deal with that now. I am off duty” (Zoë cited in 1 p.17). Amidst such attitudes, it follows that opportunities for students to witness role modelling of presence among the hospital nurses become diminished. Hence, the workloads of hospital nurses need to be re-constituted so that presence is addressed in any tools used for evaluating workloads. That way, the role that nurses have in caring to restore health will become valued. Therefore, there is a need to raise the emphasis in education and practice.

\section{I ncluding caring in practice}

While nurse educators have recognised the obligation to emphasise presence in undergraduate programmes ${ }^{[16,17]}$, the theory of presence can be presented, but it must also be reinforced in practicum experiences and in clinical assessments. Nurses being exposed to the theory of care could not envisage the application to practice, but those who listened to the care-related narratives of nurse clinicians recognised how they could apply the characteristics of caring, and presence to their own practice ${ }^{[16]}$. The role of presence as a clinical competency is enhanced when the clinical tutor, clinical nurse and the student engage in meaningful reflection about care in practice ${ }^{[16]}$. The theory needs to be reinforced through modelling, but providing time for this provides additional challenges for nurses if students perceive that acquisition of clinical skills indicate mastery of being a nurse ${ }^{[27]}$. Nurse educators should support their clinical colleagues by pointing out presence that they observe with individual nurses providing clinical care when they are with students and whilst they are engaging with their clinical colleagues. The perception is reinforced when presence is formally assessed.

As illustrated earlier, there is increasing emphasis on hospital nursing care being measured as the execution of technical skills. The lack of appreciation of presence as a core component of nursing competence has either resulted in an assumption that presence is embedded in nursing care, and, therefore, does not need to be assessed separately, or it has resulted in an inadvertent omission of the concept as a core competency. I would argue that if presence, even at a beginning level, is not assessed, then it would appear not to be valued. Thus both academic and clinical hospital nurses need to argue that presence as the defining principle of nursing must be included as an assessment component. The notion of presence can be extrapolated through measurements of attentiveness, connectedness, and being cognisant of patient individuality when assessing and making connections between the assessment findings and the patient's well-being in order to provide care. Inclusion of presence as a competency, and acknowledgement of the progressive phases of presence will add to the call to measure hospital nursing on more than the technical-based frameworks and the provision of optimal care. It will reinstate the art and presence of the nurse.

\section{Conclusion}

This paper argues that nurses who engage in caring behaviours demonstrate presence by being with their patients and by being responsive to their patients' perspectives. It is proposed that the concept of presence must be deliberately and systematically emphasised in undergraduate programmes. Acknowledgement of the progressive phases of presence, and inclusion of presence as a competency will substantiate the argument that nursing is more than the technical-based frameworks and presence is the key underpinning principle of optimal care. However, for the concept of presence to be successfully reinforced in hospital nursing, it must be formally valued, and role modelled in the workplace. Nurses need to argue because presence is the defining principle of nursing care, it must be measured as part of workload assessments.

\section{References}

[1] Mercer C, 'Being There' when one's spouse is hospitalised in a non-local tertiary setting. 2006, Massey University: Palmerston North, New Zealand.

[2] Noyes J, The impact of knowing your child is critically ill: a qualitative study of mothers' experiences. Journal of Advanced Nursing. 1999; 29: 427-435. PMid:10197943 http://dx.doi.org/10.1046/j.1365-2648.1999.00906.x

[3] Minicucci D, A review and synthesis of the literature: the use of presence in the nursing care of families. Journal of the New York State Nurses Association. 1998; 29: 9-15. 
[4] Swanson K, Nursing as informed caring for the well-being of others. Image: Journal of Nursing Scholarship.1993; 25: 352-357. PMid:8288305 http://dx.doi.org/10.1111/j.1547-5069.1993.tb00271.x

[5] Melnechenko K, To make a difference: nursing presence. Nursing Forum. 2003; 38: 18-24. PMid:12894628 http://dx.doi.org/10.1111/j.1744-6198.2003.tb01207.x

[6] Godkin J and Godkin L, Caring behaviors among nurses: Fostering a conversation of gestures. Health Care Management Review. 2004; 29: 258-267. PMid:15357236 http://dx.doi.org/10.1097/00004010-200407000-00011

[7] Watson J and Foster R, The attending nurse caring model ${ }^{\circledR}$ : integrating theory, evidence and advanced caring-healing therapeutics for transforming professional practice. Journal of Clinical Nursing. 2003; 12: 360-365. PMid:12709110 http://dx.doi.org/10.1046/j.1365-2702.2003.00774.x

[8] Watson J, Can an ethic of caring be maintained? 30th Anniversary invited editorial. Journal of Advanced Nursing. 2006; 54: 257-259. http://dx.doi.org/10.1111/j.1365-2648.2006.03848_2.x

[9] Jones T, A holistic framework for nursing time: Implications for theory, practice and research. Nursing Forum. 2010; $45: 185-196$. PMid:20690994 http://dx.doi.org/10.1111/j.1744-6198.2010.00180.x

[10] Shipley S, Listening: A Concept Analysis. Nursing Forum. 2010; 45: 125 - 134. PMid:20536762 http://dx.doi.org/10.1111/j.1744-6198.2010.00174.x

[11] Heijkenskjöld K, Ekstedt M, and Lindwall L, The patient's dignity from the nurse's perspective. Nursing Ethics. 2010; 17: 313-324. PMid:20444773 http://dx.doi.org/10.1177/0969733010361444

[12] Benner P, P. B, and S. R, Jean Watson: Philospohy and science of caring, in Nursing Theorists and their work, M.-T. A, ed., The C.V. Mosby Company: St Louis, 1989.

[13] Tamayo G, et al., Caring for the caregiver. Oncology Nursing Forum. 2010; 37: 50-59. PMid:20044332 http://dx.doi.org/10.1188/10.ONF.E50-E57

[14] Gustafsson C, Asp M, and I. Fagerberg, Municipal night nurses' experience of the meaning of caring. Nursing Ethics. 2009; 16: 559-612. PMid:19671646 http://dx.doi.org/10.1177/0969733009106652

[15] Watson J, Caring theory as an ethical guide to administrative and clinical practices. Nursing Administration Quarterly. 2006; 30: 48-56. PMid:16449884

[16] Adamski M, Parsons V, and Hooper C, Internalizing the Concept of CARING: An examination of student perceptions when nurses share their stories. Nursing Education Perspectives. 2009; 30: 358-361. PMid:19999936

[17] Christiansen B, Cultivating authentic concern: Exploring how Norwegian students learn this key nursing skill. Journal of Nursing Education. 2009; 48: 429-434. PMid:19681531 http://dx.doi.org/10.3928/01484834-20090518-03

[18] Noel D, Occupational Health Nursing Practice through the Human Caring Lens. Americal Association of Occupational Health Nursing Journal. 2010; 58: 17-24.

[19] Watson J, Caring theory as an ethical guide to administrative and clinical practices. Nursing Administration Quarterly. 2006; 30: 48-56. PMid:16449884

[20] Abbey J, et al., Clinical placements in residential aged care facilities: The impact on nursing students' perception of aged care and the effect on career plans. Australian Journal of Advanced Nursing. 2006; 23: 14-19. PMid:16800215

[21] Davis L, A phenomenological study of patients expectations concerning nursing care. Holistic Nursing Practice. 2005; 19: 126-133. PMid:15923939

[22] Arman M and Rehnsfeldt A, The 'little extra' that alleviates suffering. Nursing Ethics. 2007; 14: 372-386. PMid:17459820 http://dx.doi.org/10.1177/0969733007075877

[23] Benner P. From novice to expert: Excellence and power in clinical nursing practice. 1984, Reading, MA: Addison-Wesley.

[24] Gay S, Meeting cardiac patients' expectations of caring. Dimensions of Critical Care Nursing. 1999; 18: 46-50. PMid:10640032 http://dx.doi.org/10.1097/00003465-199907000-00012

[25] Björkström M, Johansson I, and Arthlin E, Is the humanistic view of the nurse role still alive - in spite of an academic education? Journal of Advanced Nursing. 2006; 54: 502-510. PMid:16671979 http://dx.doi.org/10.1111/j.1365-2648.2006.03845.x

[26] Brinkman A, Occupational stress in hospitals - a nursing perspective. Kai Tiaki Nursing New Zealand. 2002: 21-23. PMid:12244815

[27] Starr K and Conley V, Becoming a registered nurse: The nurse extern experience. The Journal of Continuing Education in Nursing. 2006; 37: 86-92. PMid:16883672 